\title{
Production of Ethanol Using Yeast Isolates on Water Hyacinth and Azolla
}

\author{
Riajul Hossain ${ }^{1}$, Miraj Kobad Chowdhury ${ }^{1}$, Sabina Yeasmin ${ }^{1 *}$ and M Mozammel Hoq² \\ ${ }^{1}$ Department of Genetic Engineering and Biotechnology, University of Dhaka, Dhaka-1000, Bangladesh, ${ }^{2}$ Department of Microbiology, University of Dhaka, \\ Dhaka-1000, Bangladesh.
}

(Received 2 December 2010; Accepted 5 February 2011)

\begin{abstract}
Fossil fuel depletion and limitations turn scientists to develop alternative fuels as well as biofuels. Cheap cellulosic biomass could be used as raw materials for production of ethanol. Water hyacinth (Eichhornia crassipes) and Azolla (Azolla pinnata) are the two biomass resources considered in this study. The purpose of this study was to produce ethanol using water hyacinth and Azolla as substrates used to produce ethanol by using two yeasts presumptively identified as Sachharomyces cerevisiae (Sc-SR4, Sc-MR8) and Kluyveromyces marxianus (Km-SR3). For saccharification, water hyacinth and Azolla were pretreated with different concentrations $(0.25$ to $1.0 \%)$ of sulphuric acid. D-glucose and reducing sugar yield was found higher for Azolla (40\% of dry weight) than water hyacinth ( $25.2 \%$ of dry weight). The ethanol yield was higher with water hyacinth, $(0.32 \mathrm{~g} / \mathrm{g}$ ethanol), than that of Azolla, $(0.20 \mathrm{~g} / \mathrm{g}$ ethanol). Acid and heat treatment both affected saccharification. The water hyacinth hydrolysate fermentation resulted in $1.9 \%(\mathrm{v} / \mathrm{v})$ ethanol by the isolate Sc-SR4 and $1.4 \%(\mathrm{v} / \mathrm{v})$ ethanol by the Sc-MR8 and thus the Sc-SR4 proved to be more efficient than Sc-MR8. Similarly, fermentation of Azolla hydrolysate gave $1.01 \%$ (v/ v) ethanol by Sc-SR4 and $0.45 \%(v / v)$ by the Sc-MR8 isolate.
\end{abstract}

Key words: Biofuel, Ethanol, Yeast, Cellulosic Substrates

\section{Introduction}

In the past several years the changing world energy situation has generated intensive discussion about biofuels ${ }^{1}$. First generation biofuel feedstock sources: sugarcane and cereal grains to produce bioethanol and biobutanol and oilseeds to produce biodiesel compete directly with needs for world food security ${ }^{2}$. Secondgeneration bioethanolic/biobutanolic biofuels will come from cultivated lignocellulosic crops or straw wastes. Algae and cyanobacteria for third generation biodiesel need transgenic manipulation to deal with 'weeds', light penetration, photoinhibition, carbon assimilation, etc. The possibilities of producing fourth generation biohydrogen and bioelectricity using photosynthetic mechanisms are being explored ${ }^{2,3}$.

At present, much focus is on the development of methods to produce ethanol from biomass that possesses high cellulose content. This cellulosic ethanol could be produced from abundant low-value material, including wood chips, grasses, crop residues, and municipal waste ${ }^{3}$. Signs of consolidation in the young biofuel industry are already surfacing. Recent deals also illustrate a trend of moving away from first-generation biofuels derived from food crops such as corn, sugarcane and oilseed, and toward the next generation, made from more plentiful lignocellulosic feed stocks such as corn stover, grasses and wood chips and other cellulosic biomass resources ${ }^{4}$. Biomass feedstocks for biofuels or the biofuel feedstocks can be of various types. The materials available often dictate the choice of feedstocks ${ }^{5}$.

The biomass feedstock can be usefully divided into three major types: sugar-containing materials (like sugar cane and sugar beets, store the energy as simple sugar), which can be fermented directly, starchy materials (starches), which can be easily hydrolyzed by enzymes or acids to fermentable sugars, and cellulosic materials (complex sugar polymers, cellulose), which are difficult to hydrolyze $^{6,7}$. Starch and sugar-derived ethanol already make relatively small but significant contribution to global energy supplies. In the recent days, the cellulosic substrates searching has gained a new speed and is continuing, some of which examples are water hyacinth ${ }^{8-10}$, sunflower stalks ${ }^{11}$ etc., which are being explored for ethanol production possibility in different laboratories. The water hyacinth is a native plant of Brazil but has been naturalized in many tropical/temperate countries. It is regarded as a nuisance because of its remarkable growth rate ${ }^{9}$.

The objectives of this study were to find out suitable cellulosic biomass for bioethanol production from Water hyacinth and Azolla pinnata to isolate yeast isolates from the water bodies of Dhaka city and its characterization and use for fermentation to produce biofuels. Moreover, optimization of fermentation so that the production process can be utilized for industrial scaling up, to create the future research opportunities regarding isolation and identification of yeast isolates and further manipulating them for producing bioethanol more efficiently.

\section{Materials and Methods}

Sample Collection

Fresh Azolla plant was collected in polythene bags from stock of grown Azolla in 1.2 by 1.5 meter pit in the botanical garden,

*Corresponding author

Dr. Sabina Yeasmin, Assistant Professor, Department of Genetic Engineering and Biotechnology, University of Dhaka, Dhaka 1000, Bangladesh

E-mail: y_sabina01@yahoo.com 
Department of Botany, University of Dhaka. Fresh water hyacinth was collected in the polythene bags from Turag River. For yeast isolation, samples were collected in plastic bottles. The samples, after collection, were labeled and taken to the laboratory as quickly as possible.

Pretreatment and Hydrolysis (saccharification) of Water Hyacinth and Azolla

For the pretreatment of Azolla, fresh Azolla plant (approximately $100 \mathrm{gm}$ ) was taken after washing in tap water. The sample was homogenized with 3 fold volume of distilled water. The homogenized sample was dried overnight at $70^{\circ} \mathrm{C}$ in an oven. The dried sample was blended to small particles by using a blender. The desired sample was passed through appropriate pore sized net to obtain the dried and powdered $(\approx 1-2 \mathrm{~mm}$ sized particle) sample ${ }^{9}$. In case of fresh water hyacinth, the sample, after washing in tap water, was chopped and then homogenized with 3 fold volume of distilled water. The rest of the pretreatment procedure of water hyacinth was same as Azolla.

Hydrolysis of Azolla was carried out by taking 3 gm of powdered sample in $100 \mathrm{ml}$ flasks containing $50 \mathrm{ml}$ of sulfuric acid of 0.25 , $0.50,0.75$ and $1.00 \%(\mathrm{v} / \mathrm{v})$. The samples in the flasks were autoclaved for four different time periods (15, 30, 45 and 60 min). The optimum concentration of sulfuric acid and optimum reaction time required was selected. The hydrolysate was filtered, neutralized with $1 \mathrm{~N} \mathrm{NaOH}$ (modified from Masamie et al. ${ }^{9}$ ) and heated at $50^{\circ} \mathrm{C}$ for 10 minute to remove or reduce the volatile compounds. Overliming was done by addition of $\mathrm{Ca}(\mathrm{OH})_{2}$ to remove other acid components ${ }^{10}$. The neutralized and detoxified hydrolysate was refiltered to remove sediments. Final volume of hydrolysate was $40 \mathrm{ml}$. In case of water hyacinth the procedure varied slightly with four different dilutions $(0.50,1.00,1.50$ and $\left.2.00 \%(\mathrm{v} / \mathrm{v}) \mathrm{H}_{2} \mathrm{SO}_{4}\right)$ and longer periods $(0.5,1$ and $1.5 \mathrm{hr})$ of autoclaving were done.

\section{Determination of D-Glucose Content and Reducing Sugar}

The determination of D-glucose and reducing sugar was carried out by DNS method ${ }^{12}$.

\section{Isolation of Yeasts}

Yeasts were isolated from the water samples collected from two different sources, Dhanmondi and Ramna lake. The serial ten fold dilution of up to $10^{-3} / \mathrm{ml}$ was done. One milliliter of each of the dilution was taken in an autoclaved petridish using a micropipette. Then molten acidified malt extract medium was poured and mixed thoroughly. After the medium has been settled, the plates were inverted and incubate at $37^{\circ} \mathrm{C}$ for about 48 hours and colonies were examined.

\section{Morphological characteristics}

On the basis of colonial morphology (color, form, elevation, margin, surface, consistency) by growing on the YM agar, the yeasts were isolated and maintained for further investigation and identification.

\section{Identification of selected isolates}

The isolated yeasts were prepared for photographing (photomicrography) of vegetative cells according to Barnett et al., ${ }^{13}$. Many of the microscopic observation were followed by Spencer et al., ${ }^{14}$. The cells were fixed onto the slides prior to the microscopic observation. Then different dyes were used for simple staining (lactophenol and cotton blue), staining of the vacuoles (neutral red), detection of glycogen (lugol agent), detection of volutin (methylene blue) and also for the detection of lipids (Sudan Black B).

Fermentation tests for different sugars ${ }^{13}$ were carried out. Physiological and biochemical tests carried out included DBB (Diazonium Blue test), carbon assimilation for various carbon sources, nitrogen assimilation for various nitrogen sources and vitamin requirements for different vitamins.

Carbon assimilation test was performed for 13 carbon compounds: D-Glucose, D-Galactose, D-Xylose, L-Arabinose, Sucrose, Maltose, $\alpha, \alpha$-Trehalose, Melibiose, Lactose, Raffinose, Starch, Glycerol, Ethanol. Nitrogen assimilation test was performed to utilize nitrate and some other nitrogen compounds as sole nitrogen source. The nitrogen compounds used were (Nitrite, Nitrate, Ethylamine, L-Lysine, Creatine, Creatinine, DTryptophan). Vitamin requirement is assessed to know the ability of the yeast isolates to grow with or without a particular vitamin in the media. The vitamins used for this test were: $\mathrm{p}$-aminobenzoic acid (PABA), Biotin, Folic acid, myo-Inositol, Nicotinic acid (Niacin), Pantothenate (Ca), Pyridoxine $\mathrm{HCl}$, Thiamin $\mathrm{HCl}$.

Besides, growth at various conditions (high osmotic pressures, high concentrations of sugar, high concentrations of salt, various temperatures, different $\mathrm{pH}$, and different medium) was observed and also some other tests (urea hydrolysis test, catalase test, hydrolysis of casein) were performed.

\section{Maintenance of cultures}

The pure culture was maintained on MYGP medium in screw cap test tube and was maintained at $4^{\circ} \mathrm{C}$.

\section{Fermentation of the Hydrolysate for Ethanol}

One loopful of yeast colony was taken from $24 \mathrm{~h}$-old fresh young cultures into sterile $10 \mathrm{ml}$ distilled water in a test tube and homogenous suspension was made by vortex mixer. One millitier of suspension was inoculated to a $50 \mathrm{ml}$ YM broth in a $150 \mathrm{ml}$ conical flask and was incubated at $30^{\circ} \mathrm{C}$ at $150 \mathrm{rpm}$ for 24 hour. $1.5 \mathrm{ml}$ of this was used to inoculate fermentation media of $50 \mathrm{ml}$. Estimation of ethanol was done by dichromate assay ${ }^{15}$. The amount of ethanol was estimated by colorimetric and titrimetric method.

\section{Results and Discussion}

Surging oil prices and a shortage of biofuel feedstocks are reviving interest in making biofuel from the cheap cellulosic substrates in fact using them as biomass. This is because biofuels are a new priority in efforts to reduce dependence on fossil fuels ${ }^{16}$. Cellulosic ethanol can have great positive impact on current the global warming situation. Again, bioethanol can impart an ecological advantage. The aquatic species like water hyacinth 
and Azolla can be a good cellulosic biomass and can be efficient in releasing sugars in their hydrolysate by cost-efficient treatments. The other part of our research was the isolation of yeasts and provisional identification of some of those which proved promising in the primary selection of the strains for bioethanol production. Interestingly, no single yeast exists which is able to utilize all possible substrates. The trend in yeast research is to develop yeast strains which use a broader range of substrates at faster rates and higher temperatures, and which are more tolerant to higher concentrations of ethanol and sugar ${ }^{17}$.

Yeast isolate was found to be efficient to produce ethanol from the selected biomass and in comparison of the biomasses, water hyacinth was found to be better.

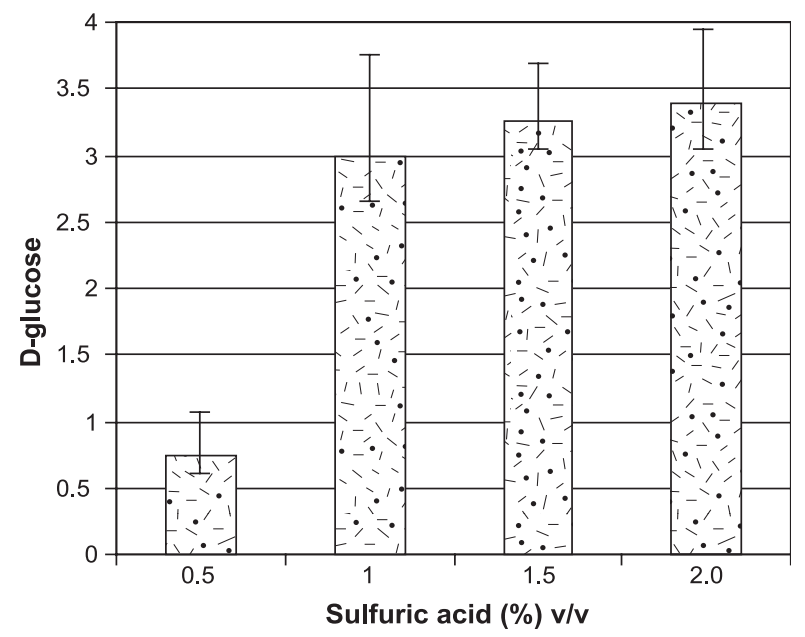

Fig 1: Effect of sulfuric acid on water hyacinth hydrolysate to release $D$-glucose at $121^{\circ} \mathrm{C}$ for $1 \mathrm{hr}$. Each value is an average of the results of three individual experiments. The error bar represents standard deviations.

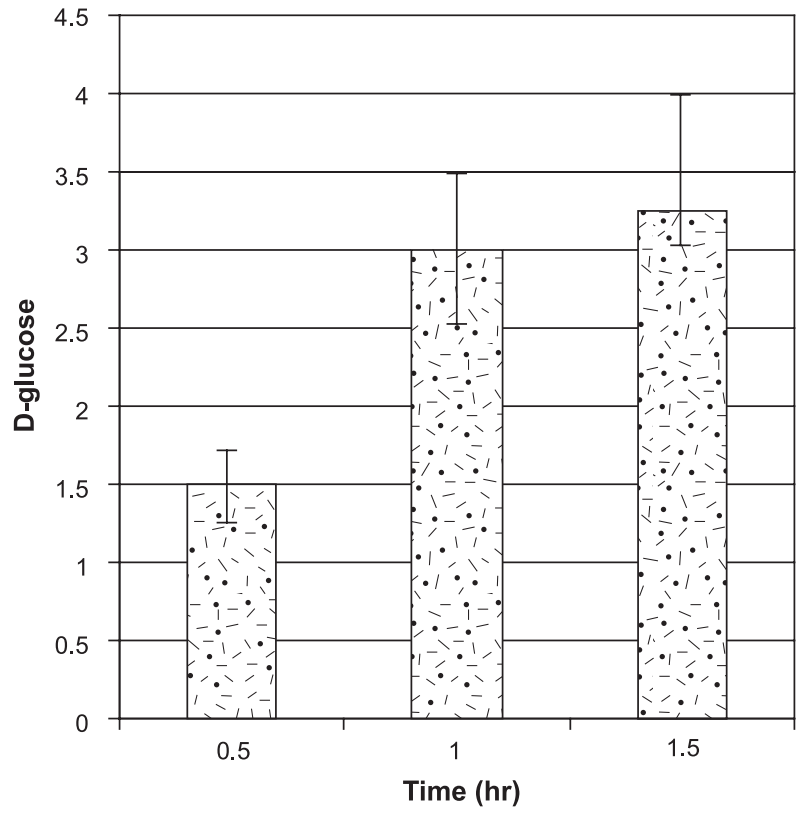

Fig 2: Effect of reaction time on D-glucose production from water hyacinth at $121^{\circ} \mathrm{C}$ with $1 \%$ sulfuric acid.
The reaction time $1 \mathrm{hr}$ and $1 \%(\mathrm{w} / \mathrm{v})$ sulfuric acid $\left(\mathrm{H}_{2} \mathrm{SO}_{4}\right)$ concentration was optimum for the hydrolysate preparation of water hyacinth to get maximum types of sugars in a cost-efficient way. The optimization has been represented in two figures (Fig. 1 and 2). The hydrolysate after processing for ready to fermentation contained $3 \mathrm{mg} / \mathrm{ml}$ D-glucose and $18 \mathrm{mg} / \mathrm{ml}$ reducing sugar (Fig. 3) .The reaction time and sulfuric acid concentration were found to be $30 \mathrm{~min}$ and $0.75 \%(\mathrm{w} / \mathrm{v})$ as optimum for the Azolla to get maximum reducing sugars in a way which will be efficient in terms of low production cost. The hydrolysate after processing for ready to fermentation contained $4 \mathrm{mg} / \mathrm{ml}$ D-glucose and 30mg/ml reducing sugars (Fig 3).

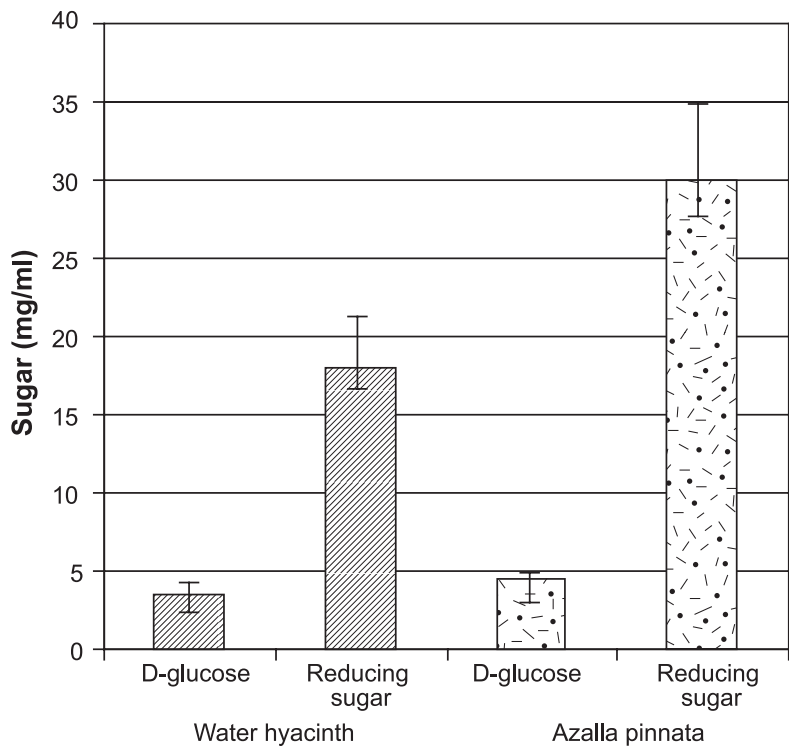

Fig 3: Production of D-glucose and reducing sugar from Azolla pinnata and water hyacinth.

\section{Isolation and Identification of Yeast Isolates}

Two isolates of Sachharomyces cerevisiae (Sc-SR4, Sc-MR8) and one isolate of Kluyveromyces marxianus (Km-SR3) were obtained. Sixteen isolates after primary selection and then based on the selective characteristics such as ability to use the hydrolysate and fermentation capability (observed by anaerobic utilization of sugars), only those three isolates were chosen for detailed study for the purpose of provisional identification of the isolates for the fermentation of plant hydrolysate. There was no major variation in the colonial characteristics of the species regarding their morphology (Table 1).

Table 1: Colonial characteristics of the yeast isolates

\begin{tabular}{lcccr}
\hline Isolates No. & Form & Surface & Color & Consistency \\
\hline Sc-SR4 & Circular & Smooth & Cream & Butyrous \\
Km-SR3 & Punctiform & Contoured & Off white & Butyrous \\
Sc-MR8 & Irregular & Smooth & Cream & Butyrous \\
\hline
\end{tabular}

All three selected isolates (Sc-SR4, Km-SR3 and Sc-MR8) were containing the vacuoles, glycogen, volutin and lipid. The 
fermentation capability of the isolates was tested on glucose, galactose, maltose, sucrose, $\alpha, \alpha$-Trehalose, melibiose, lactose, raffinose, starch, D-Xylose.

The isolates selected were studied for various physiological and biochemical features as these characteristics are important for identification.

Test with Diazonium blue B (DBB) was negative indicating that all three yeast isolates were not basidiomycetous.

The outcome of the different tests was compared with the standard organisms described in Barnett et al. ${ }^{13}$. The Sc-MR8 was negative for all of the nitrogen (unable to utilize) sources tested as sole source. Some of the results deviated from the standard one. The isolate Sc-SR4 showed negative result in the fermentation tests with the sugar $\alpha, \alpha$-trehalose, but the standard one could ferment it otherwise. The isolate $\mathrm{Km}$-SR3 was able to ferment melibiose and unable to do so with maltose. But the standard organism could ferment maltose but not melibiose. The isolate Sc-MR8 showed negative result for the sucrose fermentation test as well ${ }^{13}$.

For the carbon and nitrogen assimilation tests, the isolates showed some deviations from the standard one described. The isolate Sc-SR4 found unable to utilize $\alpha, \alpha$-trehalose but utilize lactose whereas the standard organism worked oppositely. The isolate Km-SR3 showed positive result in the carbon assimilation test that means it could ferment D-xylose and melibiose whereas the standard organism could not. Finally, the Sc-MR8 isolate was unable to utilize glycerol as sole carbon source but the standard organism utilized melibiose as sole carbon source rapidly.

In the nitrogen assimilation test, the isolate Sc-MR8 perfectly matched with the tested nitrogen sources as sole nitrogen source. But the isolate Sc-SR4 deviated from the standard one by being able to assimilate lysine as sole nitrogen source where the standard organism was unable to do so. The isolate Km-SR3 differed from the standard organism in case of nitrite utilization as it was able to utilize nitrite whereas the standard organism did the otherwise. The test of ability to use nitrate as sole source of nitrogen is a valuable aid to identifying yeasts, since about one quarter of all the species utilize nitrate and this ability is a uniform feature of all the strains within the species. Other than nitrate some other nitrogen compounds, such as nitrite, ethylamine and L-lysine have also been found to be useful substrates for nitrogen assimilation.

Ability of yeast to tolerate high osmotic pressure ( $\mathrm{NaCl}$ was used as the salt on which the strains to be tested) showed that all the isolates were able to grow on $5 \%$ salt, but ability decreased as salt concentration increased with no growth at $16 \%$ (Fig. 4).

Urea hydrolysis test demonstrated that all of the isolates tested were urease negative. Catalase test confirms the presence of this enzyme in all the yeast isolates. Only Km-SR3 isolate was unable to hydrolyse casein.

Growth at various temperatures was done to observe the yeast isolates ability to grow at different temperatures (Fig. 5).

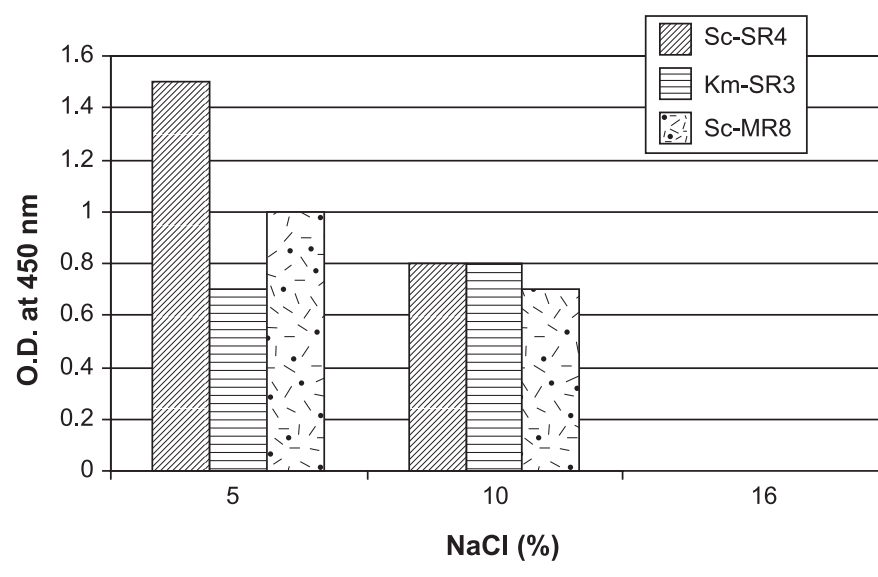

Fig 4: Growth of the yeast isolates at different concentrations of salt

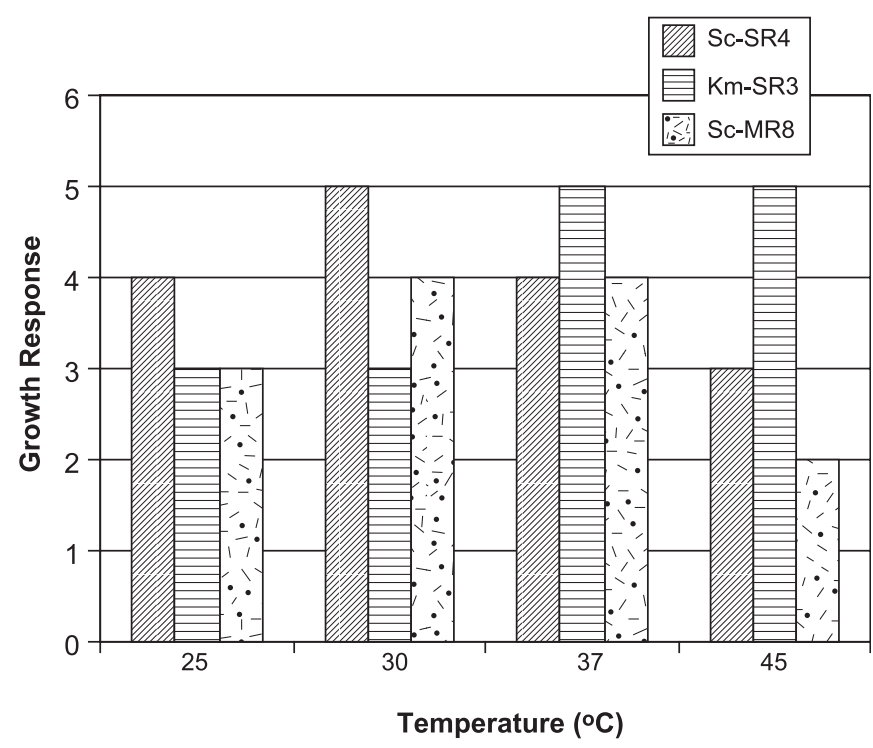

Fig 5: Growth response of the isolates at different temperatures (the numbers in Y-axis represents visual examinations)

By using phosphate buffer different $\mathrm{pH}$ of the media were created and the yeasts ability to grow on those media was assessed visually in this test. The pH optima for the two isolates Sc-MR8 and KmSR3 was found 5.5 but Sc-SR4 showed good growth at both of the 3.5 and 5.5 .

\section{Efficiency of Ethanol Fermentation}

The fermentation was done taking $50 \mathrm{ml}$ hydrolysate media in a $250 \mathrm{ml}$ flask with $3 \%$ yeast inoculums at $\mathrm{pH} 5$ and the temperature $30^{\circ} \mathrm{C}$. The estimated ethanol was found in water hyacinth hydrolysate as $1.9 \%(\mathrm{v} / \mathrm{v})$ for the isolate Sc-SR4 and $1.4 \%(\mathrm{v} / \mathrm{v})$ for Sc-MR8. The estimated ethanol was found in Azolla hydrolysate as $1.01 \%(\mathrm{v} / \mathrm{v})$ for the isolate Sc-SR 4 and $0.45 \%(\mathrm{v} /$ v) for the isolate Sc-MR8 (Fig. 6). 


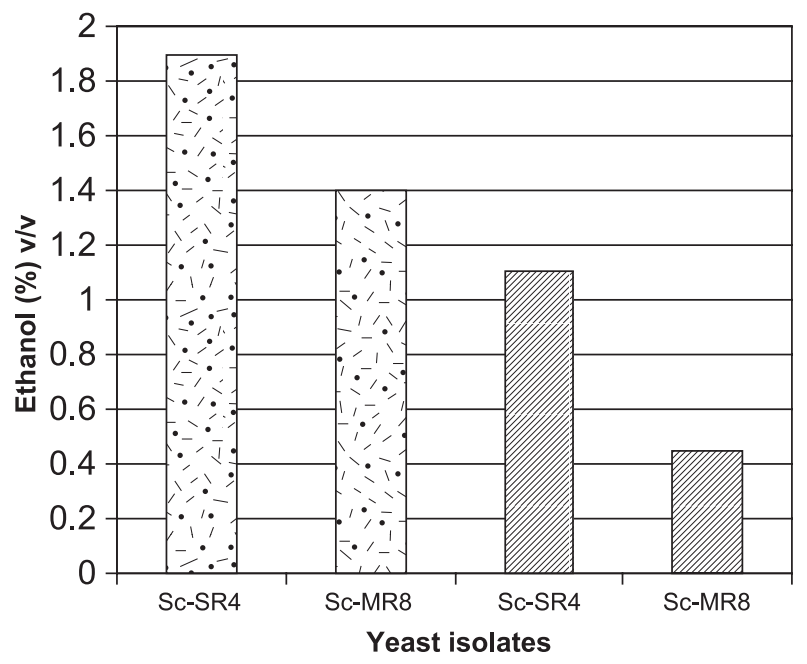

Fig 6: Ethanol fermentation on water hyacinth (solid bars) and Azolla (hollow bars)

A $24 \mathrm{hr}$ old culture of each of the two selected isolates for fermentation was inoculated at $3 \%(\mathrm{v} / \mathrm{v})$ in the hydrolysate media. The results suggested that the water hyacinth and Azolla supported $0.32 \mathrm{~g} / \mathrm{g}$ and $0.20 \mathrm{~g} / \mathrm{g}$ ethanol respectively. These results revealed that Azolla is not a better substrate than water hyacinth for bioethanol production. The ethanol yield can be compared with the previous reports made by Nigam ${ }^{10}$ where it was shown that the ethanol yield was $0.35 \mathrm{~g} / \mathrm{g}$ when the hydrolysate was treated by boiling and overliming which is consistent with our findings. The water hyacinth hydrolysate fermentation achieved $1.9 \%(\mathrm{v} / \mathrm{v})$ ethanol by Sc-SR4 isolate and $1.4 \%(\mathrm{v} / \mathrm{v})$ by the Sc-MR8 isolate and thus the isolate ScSR4 proved to be more efficient than the other one, Sc-MR8. Similarly, Azolla hydrolysate fermentation yielded 1.01\% (v/ v) ethanol in the broth by Sc-SR4 isolate and $0.45 \%(\mathrm{v} / \mathrm{v})$ by the Sc-MR8 isolate. All of these ethanol concentrations were the results of the fermentation of the two plants hydrolysate concentrated to $40 \mathrm{~g} / \mathrm{L}$ reducing sugar. However, comparing to the sugar content found in the 1 liter hydrolysate of both of the two substrates achieved nearly the same concentration of ethanol which was $0.7 \%(\mathrm{v} / \mathrm{v})$ in their original hydrolysate (without concentrating the reducing sugars).

\section{Conclusion}

This research will certainly create a direction of efficient and cheap cellulosic substrates utilization regarding the biomass sources. The target is to produce ethanol from cellulosic substrates which are not used for human and animals. In the future, we hope that there will be cellulosic ethanol industry in our country to meet the transportation fuel requirements and there will be lots of ethanol filling stations in many places of the country.

\section{Acknowledgement}

This research work was supported by a grant from the Biotechnology Research Centre, University of Dhaka, Dhaka 1000, Bangladesh.

\section{References:}

1. von Braun Joachim and Pachauri RK 2005-2006. The Promises and Challenges of Biofuels for the Poor in Developing Countries. IFPRI Annual Report Essay. pp 1-3. Heidi Fritschel. Graphic Communications, Inc.

2. Gressel Jonathan. 2008. Transgenics are imperative for biofuel crops. Plant Science.174: 246-263.

3. "biofuel.” 2009. In Encyclopcedia Britannica. Retrieved from http:// www.britannica.com/EBchecked/topic/967492/biofuel.

4. Waltz Emily. 2008. "Cellulosic Ethanol Booms Despite Unproven Business Model. Nature Biotechnol. 26 (1).

5. Spencer JFT and Spencer DM. 1997. Yeasts in Natural and Artificial Habitats. Springer Verlag.

6. Prescott and Dunn. 2004. Industrial Microbiology. Macmillian Publishers. pp-835-840.

7. US Department of Energy-Energy efficiency and Renewable energy. http:/ /www.eere.energy.gov.

8. Isarankura NC, Tantimongcolwat T, Kongpanpee T, Prabkate P, Prachayasittikul V. 2007. Appropriate Technology for the Bioconversion of Water hyacinth (Eichhornia crassipes) to Liquid Ethanol: Future Prospects for Community Strengthening and Sustainable Development. Department of Clinical Microbiology, EXCL Journal. 6, pp 167-176.

9. Masami G, Ogawa O, Usui IY and Naoto U. 2008. Ethanol production from the water hyacinth Eichhornia crassipes by yeast isolated from various hydrospheres. African J Microbiolo Res. 2: 110-113.

10. Nigam JN. 2002. Bioconversion of water-hyacinth (Eichhornia crassipes) hemicellulose acid hydrolysate to motor fuel ethanol by xylose fermenting yeast. J Biotechnol. 97: 107-116.

11. Sharma SK, Krishan LK, Harmeet SG. 2002. Fermentation of enzymatically sachharified sunflower stalks for ethanol production and its scale up. Biores Technol. 85: 31-33.

12. Yemm EW and Willis AJ. 1954. The Estimation of Carbohydrates in Plant Extracts by Anthrone, $J$ biol Chem. 57: p-508.

13. Barnett JA, Payne RW, and Yarrow D. 2007. Yeasts: Characteristics and Identification. Cambridge University Press. New York. pp 1-9.

14. Evans IH.1996. Yeast Protocols, Methods in Cell and Molecular Biology by. Humana Press, Totowa, New Jersey. pp 383-390.

15. www.outreach.canterbury.ac.nz

16. Martha JG, Elizabeth MGray, and Patricia AT. 2008. Biofuels and Biodiversity: Principles for Creating Better Policies for Biofuel Production. Conservation Biol. 22(3): 602-609.

17. Schenberg AC and da Costa, SOP. 1987. CRC Critical Reviews in Biotechnology. 6(4):323.

18. Aboud AAO, Kidunda RS and Osarya J. 2005. Potential of water hyacinth (Eicchornia crassipes) in ruminant nutrition in Tanzania, Livestock Res Rural Development. 17 (8). 